\title{
Psychological capital as a moderator in the relationship between occupational stress and organisational citizenship behaviour among Nigerian graduate employees
}

\begin{tabular}{|c|c|}
\hline \multicolumn{2}{|c|}{$\begin{array}{l}\text { Authors: } \\
\text { John K. Aderibigbe }{ }^{1} \text { (1) } \\
\text { Themba Q. Mjoli }{ }^{1} \text { (1) }\end{array}$} \\
\hline \multicolumn{2}{|c|}{$\begin{array}{l}\text { Affiliations: } \\
{ }^{1} \text { Department of Industrial } \\
\text { Psychology, University of } \\
\text { Fort Hare, South Africa }\end{array}$} \\
\hline \multicolumn{2}{|c|}{$\begin{array}{l}\text { Corresponding author: } \\
\text { John Aderibigbe, } \\
\text { johnaderibigbe1@gmail.com }\end{array}$} \\
\hline \multicolumn{2}{|c|}{$\begin{array}{l}\text { Dates: } \\
\text { Received: } 10 \text { Jan. } 2018 \\
\text { Accepted: } 24 \text { July } 2018 \\
\text { Published: } 20 \text { Sept. } 2018\end{array}$} \\
\hline \multicolumn{2}{|c|}{$\begin{array}{l}\text { How to cite this article: } \\
\text { Aderibigbe, J.K., \& Mjoli, T.Q. } \\
\text { (2018). Psychological capital } \\
\text { as a moderator in the } \\
\text { relationship between } \\
\text { occupational stress and } \\
\text { organisational citizenship } \\
\text { behaviour among Nigerian } \\
\text { graduate employees. SA } \\
\text { Journal of Human Resource } \\
\text { Management/SA Tydskrif vir } \\
\text { Menslikehulpbronbestuur, } \\
\text { 16(0), a1030. https://doi.org/ } \\
\text { 10.4102/sajhrm.v16i0.1030 }\end{array}$} \\
\hline \multicolumn{2}{|c|}{$\begin{array}{l}\text { Copyright: } \\
\text { (C) 2018. The Authors. } \\
\text { Licensee: AOSIS. This } \\
\text { is licensed under the } \\
\text { Creative Commons } \\
\text { Attribution License. }\end{array}$} \\
\hline \multicolumn{2}{|l|}{ Read online: } \\
\hline 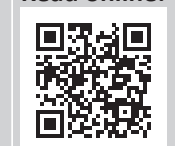 & $\begin{array}{l}\text { Scan this QR } \\
\text { code with your } \\
\text { smart phone or } \\
\text { mobile device } \\
\text { to read online. }\end{array}$ \\
\hline
\end{tabular}

Orientation: It is a documented fact that occupational stress is widespread worldwide. Moreover, there are clear signs of many variables that affect Nigerian graduate employees, which are most likely to cause severe occupational stress, and this, in turn, could negatively affect employees and their organisational ability to demonstrate citizenship behaviour.

Research purpose: The purpose of this study was twofold: firstly, to examine the nature of relationship between occupational stress and organisational citizenship behaviour, and, secondly, to investigate whether psychological capital significantly moderates the relationship between occupational stress and organisational citizenship behaviour.

Motivation for the study: The study was conducted to demonstrate whether the presence of psychological capital could result in a better level of employee performance, even as employees experience a certain level of occupational stress. In view of the above, the study might have contributed to form a new model of psychological intervention for occupational stress and organisational citizenship behaviour.

Research approach/design and method: The study adopted the positivist explanatory crosssectional (survey) research design to systematically sample opinions of 1532 male and female graduate employees across various sectors of the Nigerian economy, using a structured and validated questionnaire and the Statistical Package for the Social Sciences (SPSS) software.

Main findings: The results showed that there was a weak positive relationship between occupational stress and organisational citizenship behaviour. Psychological capital significantly moderated the relationship between occupational stress and organisational citizenship behaviour.

Practical/managerial implications: Human resource managers should develop psychological capital in employees in order to increase the level of organisational performance and reduce the negative impact of occupational stress.

Contribution/value-add: Recommendations of the study could assist in training and developing effective workforce capacity towards improving the economy of the nation.

\section{Introduction}

Scholars have linked challenges that are related to employee performance in current employment with high levels of occupational stress (Baxter, 2010; Laschinger, 2011; Shafaghat, Zarchi, \& Kavosi, 2018). In the same manner, studies have shown that occupational stress is significantly related to both task-related work behaviour and non-task-related work behaviour of employees (Adebiyi, 2013; Arogundade \& Lawal, 2016; Niks, de Jonge, Gevers, \& Houtman, 2018). The World Health Organization (WHO) has also reported occupational stress as a global epidemic (WHO, 2010). Obviously, the consequence of an increasingly strenuous work environment is evident in Nigerian work settings, as cases of job dissatisfaction, a high rate of absenteeism, employee intention to quit, labour turnover and poor job performance (contrast to organisational citizenship behaviour) remain evident among graduate employees in Nigeria (Adebayo \& Ogunsina, 2011; Adebiyi, 2013; Adetayo, Ajani, \& Olabisi, 2014; Arogundade \& Lawal, 2016).

So far, broad studies over the years have centred on identifying the stressors (Brynien \& Igoe, 2016; Paillé, 2011). The literature further reveals that most studies conducted on occupational stress have concentrated on determinants, as opposed to results, such as employee performance, 
turnover intention, turnover behaviour and employee productivity (American Psychological Association, 2013; Goh, Pfeffer, \& Zenios, 2015). Hence, few scientific investigations have been conducted to devise psychological intervention strategies to ameliorate the situation and ensure organisational citizenship behaviour (Ahmad, Hussain, Saleem, Qureshi, \& Mufti, 2015; Niks et al. 2018). Furthermore, although there is an increasing consideration of the phenomenon of organisational citizenship behaviour by researchers, a thorough review of the literature shows a lack of agreement about the scope of the concept (Farzianpour, Foroushani, Kamjoo, \& Hosseini, 2011). However, the current study sought to empirically examine the moderating role of psychological capital (PsyCap) in the relationship between occupational stress and organisational citizenship behaviour in order to fill the existing vacuum identified in the literature.

\section{Research purpose}

The purpose of the study is twofold. Firstly, the study seeks to examine the nature of relationship between occupational stress and organisational citizenship behaviour. Secondly, the study seeks to investigate if there is a significant moderating role of PsyCap in the relationship between occupational stress and organisational citizenship behaviour.

\section{Literature review}

\section{Organisational citizenship behaviour}

Organisational citizenship behaviour is an essential phenomenon in the formal work setting because of its potency to facilitate interpersonal relationships among employees, and also to increase organisational performance (Kumari \& Thapliyal, 2017; Pradhan, Jena, \& Bhattacharya, 2016). Organisational citizenship behaviour is an alternative form of performance behaviour, which is differentiated from the traditional performance that relies heavily on official assignments and tasks (Karolidis, 2016). For instance, having subordinates who are highly engaged in organisational citizenship may improve managers' efficiency by allowing them to devote a greater amount of time to long-range planning matters. Hence, managers, employees and the organisations at large benefit from the positive behaviours (Lelei, Chepkwony, \& Ambrose, 2016; Nawazi \& Gomes, 2018). These behaviours are explained by concepts such as pro-social behaviours, extra-role behaviours, contextual performance, spontaneous behaviours or organisational citizenship behaviour.

\section{Occupational stress}

Occupational stress is a negative career-related concept that generates concerns among career holders, and it has the ability to influence individual and organisational outcomes (Beheshtifar \& Nazarian, 2013). In other words, occupational stress is a negative phenomenon, the occurrence of which often stimulates an unpleasant response to the work environment making it appear threatening to the employees. Moreover, prolonged occupational stress could manifest itself physically, emotionally and psychologically in the lives of the affected employees.

The commonly reported physical symptom of occupational stress is a headache, which makes the affected employees unconsciously tense in their necks, foreheads and shoulder muscles (Chandra \& Parvez, 2016). The other known symptoms of occupation stress are digestive problems, ulcers, hypertension, anxiety and inordinate sweating, coronary illness, strokes and even male pattern baldness (Chandra \& Parvez, 2016). Emotionally, an affected employee frequently displays nervousness, outrage, depression, fractiousness, frustration to ordinary issues, dementia and an absence of focus for any assignment, because the mind of the individual is negatively impacted. The psychological manifestations of occupational stress, on the other hand, include withdrawal from society, phobias, compulsive behaviours, eating disorders and night fears (Chandra \& Parvez, 2016).

\section{Psychological capital}

The term 'PsyCap' is a composite construct that is defined according to Luthans, Avolio, Avey and Norman (2007) as:

a person's positive mental state of improvement, which is described by: (1) having confidence (self-efficacy) to take on and put in the needed effort so as to prosper at challenging responsibilities; (2) making a positive attribution (optimism) about succeeding now and in the future; (3) determining toward goals and, when necessary, diverting ways to objectives (hope) with a specific end goal to succeed; and (4) when affected by issues and afflictions, managing, enduring and even going past (resilience) to reach success. (p. 3)

According to Aliyev and Tunc (2015), PsyCap is a collection of abilities such as self-efficacy, optimism and endurance that are open to improvement, and it implies more than the collection of the aforementioned skills.

Specifically, capital signifies the quality of individuals' assets (human capital) as well as in connection with other constructs such as social capital, cultural capital and intellectual capital (Amunkete, 2015). The term 'PsyCap' also denotes individual motivational inclinations that accumulate through desirable psychological concepts such as optimism, resilience, hope and efficacy (Luthans et al., 2007). Besides, PsyCap is recognised in the situation of a venture in psychic resources that results in getting realistic incentives from the current moment while also brightening the prospect of future benefits. It is about the condition of the segment of an individual's inner life (Amunkete, 2015).

\section{Relationship between occupational stress and organisational citizenship behaviour}

In a recent descriptive correlational study (Nourani, Kohansal, Esmaily, \& Hooshmand, 2016) on the relationship between organisational citizenship behaviour and occupational stress among 122 midwives at Mashhad, Iran, it was found that there is a significant negative association between organisational citizenship behaviour and occupational stress. Likewise, Arogundade and Lawal (2016) investigated 
the influence of perceived occupational stress on the organisational citizenship behaviour among 300 male and female bankers in Lagos, Nigeria, using a simple random sampling technique. Although the results of the study revealed that there is no significant difference in the levels of organisational citizenship behaviour that were exhibited by bankers with higher stress levels and those with lower stress levels, there is an inverse relationship between occupational stress and organisational citizenship behaviour.

Moreover, Soo and Ali (2016) studied the linkage between occupational stress and organisational citizenship behaviour among a sample of 472 bankers in Malaysia and found that there is a significant negative impact of occupational stress on organisational citizenship behaviour. In the same vein, Gregory, Yitzhak and Steffen (2016) scientifically examined the proposed need to distinguish between self-initiated and organisationally imposed overload in studies of work stress, using three samples, which consisted of 116 male and female full-time employed students in three countries, some nursing staff of six private hospitals in Switzerland and 161 middle manager-supervisor dyads in Switzerland. The study revealed in its findings that self-initiated imposed overload is significantly, positively related to organisational citizenship behaviour, but organisationally imposed overload is not a significant predictor of organisational citizenship behaviour.

Furthermore, Ikonne and Madukoma (2016) conducted a survey on the relationship among organisational citizenship behaviour, job stress and satisfaction among 109 librarians in some selected universities around the south-west region of Nigeria and found that there is a significant negative relationship between organisational citizenship behaviour and job stress. In addition, Uzonwanne (2014) conducted a survey research on depression, anxiety and stress as correlates of organisational citizenship behaviour, using the accidental sampling technique to sample 151 female and 149 male employees of oil and gas companies in Ogun State, Nigeria. The outcomes of their research showed that there is a significant positive relationship between occupational stress and organisational citizenship behaviour. The findings of the study also indicated that although there was a statistical positive relationship between the two variables, the observed positive relationship was weak considering the $r$ value of 0.118 , which is close to 0 .

\section{Psychological capital as a moderator in the relationship between occupational stress and organisational citizenship behaviour}

Aybas and Acar (2017) surveyed the mediating and moderating roles of PsyCap in the effects of opportunity enhancing human resource (HR) practices and working conditions on work engagement among 555 white-collar employees of private companies from different sectors in Turkey by using a convenience sampling method and a validated questionnaire and sampled the views of respondents about the variables under consideration in the study. The results of the statistical analysis of data showed that PsyCap partially moderated and mediated the effects of opportunity enhancing HR practices and working conditions on work engagement.
Likewise, Wang, Liu, Zou, Hao and Wu (2017) conducted a cross-sectional survey research that investigated the mediating role of PsyCap on occupational stress, organisational support and work engagement among a sample of 1016 female nurses that was drawn from the population of nurses in the general hospitals in Shenyang, Liaoning Province, China. A validated questionnaire was used to collect data from all the participants in the study. The research findings showed that PsyCap and its components of hope and optimism are significant mediators of the relationships among work stress, work engagement and rewards.

In addition, Shaheen, Bukhari and Adil (2016) surveyed the moderating role of PsyCap in the relationship between organisational support and organisational citizenship behaviour among a sample of 325 employees in public and private sector banks of Islamabad and Rawalpindi cities in Pakistan by using a convenience sampling technique and a validated questionnaire to gather information from the participants. The study discovered and established from its findings that PsyCap significantly enhanced the observed positive relationship between organisational support and organisational citizenship behaviour.

Correspondingly, Li et al. (2015) studied the mediating role of PsyCap on the association between occupational stress and burnout among a sample of 1239 male and female bankers drawn from the population of bankers in the state-owned banks in Liaoning in China by using a random sampling technique. The study adopted a cross-sectional survey research design and used a validated questionnaire to collect data from the participants. The findings of the study indicated that PsyCap is generally a mediator between occupational stress and job burnout among Chinese bank employees.

\section{Conceptual model}

Based on the past studies reviewed and on logical grounds, a conceptual model was developed indicating the hypothesised relationship between occupational stress and organisational citizenship behaviour, and the moderating role of PsyCap. Organisational citizenship behaviour is depicted as the dependent variable, while occupational stress is the independent variable, whereas PsyCap is shown as the moderating variable. The conceptual model, demonstrated in Figure 1, indicates the moderating role of PsyCap in the

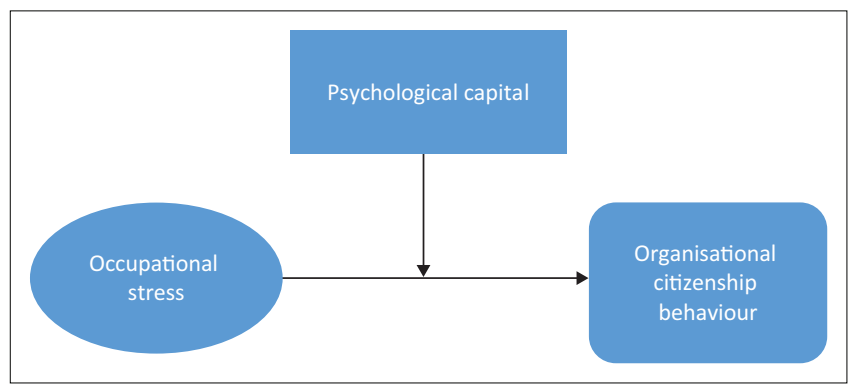

FIGURE 1: Psychological capital as a moderator of the relationship between occupational stress and organisational citizenship behaviour. 
relationship between occupational stress and organisational citizenship behaviour.

\section{Statement of hypotheses}

\section{Hypothesis 1}

$\mathbf{H}_{0}$ : Occupational stress is not significantly positively correlated with organisational citizenship behaviour.

$\mathbf{H}_{\mathbf{1}}$ : Occupational stress is significantly positively correlated with organisational citizenship behaviour.

\section{Hypothesis 2}

$\mathbf{H}_{\mathbf{0}}$ : Psychological capital is not a significant moderator of the relationship between occupational stress and organisational citizenship behaviour.

$\mathbf{H}_{\mathbf{1}}$ : Psychological capital is a significant moderator of the relationship between occupational stress and organisational citizenship behaviour.

\section{Research methodology Research design, sample and procedure}

The study adopted a positivist explanatory cross-sectional (survey) research design. The explanatory cross-sectional (survey) research was considered appropriate for the study because the research used the positivist approach by means of quantitative data generation and hypotheses testing (Bhattacherjee, 2012). The chosen research design was also considered appropriate in the study because the study cut across the private and public sectors of the national economy, and thus incorporated diverse industries.

The stratify type of probability (two-stage North Carolina Center for Public Health Preparedness' [2013] sampling scheme) technique was adopted along with the Research Advisor's (2006) sample size calculation table, and used in calculating the appropriate sample size of the study. According to the Federal Ministry of Women Affairs and Social Development (2008), there were a total number of 40567978 male and female employees across industries in Nigeria as of 2007. In applying the stratify sampling method as recommended by the North Carolina Center for Public Health Preparedness, 10\% of 40567978 was calculated at the first stage, which reduced the number to 4056797 . Again, at the second stage, $10 \%$ of 4056797 was calculated. Consequently, the result further reduced the number to 405679 . Nevertheless, at this point, the researchers subjected the derived figure of 405679 to the recommendation of the Research Advisor (2006), which approves a sample size of 1532 (at 95\% level of confidence and 2.5\% margin of error) out of an approximate population of 500000 for a national survey. Hence, the researchers were $95 \%$ confident of the population sampled being a true representation of the study's targeted population. Thus, a total of 1532 male and female graduate employees formed the sample size of the study.

In addition, the convenience and purposive types of nonprobability sampling technique were employed in selecting participants for the study. Firstly, the convenience sampling technique was applied in selecting three most suitable states (Oyo, Osun and Lagos States) out of the 36 states in Nigeria, as the sites of the field work. The rationale for selecting the three states is that each of them houses one or the other of the renowned public and private universities (University of Ibadan, Obafemi Awolowo University and the Pan-Atlantic University) where the study samples were offered part-time postgraduate admissions for MBA programmes as workingclass postgraduate students with a minimum of 3-year employment experience. Another reason for adopting the convenience sampling technique was because the fieldwork became easier when the participants were met in groups at conducive places such as in the lecture rooms and relaxation centres within the university premises. Furthermore, as the study was designed only for the graduate employees, the purposive sampling technique was also introduced and applied to ensure that participants in the study were employed during the period of the field work, and that they were graduates of universities and polytechnics.

The sample consisted of $916(60 \%)$ male and $616(40 \%)$ female graduate employees from 19 sectors of the Nigerian economy. Among the participants, 202 (13.2\%) were graduate employees from the educational sector, $38(2.5 \%)$ from the research institutes, 51 (3.3\%) from the transportation sector, $291(19 \%)$ from the finance and insurance sector, $83(5.4 \%)$ from the fast-moving consumer goods (FMCGs) industry, $21(1.4 \%)$ from the commercial sector, 70 (4.6\%) from the healthcare sector, $8(0.5 \%)$ from the aviation sector, 77 (5.0\%) from the agricultural sector and 57 (3.7\%) from the information technology sector. All participants were Nigerians English speakers. The participants' ages ranged from 20 to 65 years old. Relatively, 974 (63.6\%) of the participants were senior staff, while the remaining 558 (36.4\%) were junior staff. Conclusively, among the participants, $730(47.7 \%)$ were employed by the government, while the remaining 802 (52.3\%) were working under the employment of private organisations.

Data were collected by means of paper-pencil inventories (structured validated questionnaires), which were distributed to employees in the large lecture auditoriums during their weekend (Saturdays) part-time professional postgraduate programmes, in the three renowned public and private universities (University of Ibadan, Obafemi Awolowo University and the Pan-Atlantic University), situated in Oyo, Osun and Lagos states of Nigeria.

\section{Measuring instruments}

Three established scales of measurement were used to assess PsyCap, occupational stress and organisational citizenship behaviour.

\section{Psychological capital}

A 24-item scale of PsyCap that was developed and validated by Luthans et al. (2007) was utilised to measure PsyCap. 
The construct consisted of self-efficacy, hope-state, optimismstate and resilience-state sub-scales, with a five-point Likerttype response format ranging from 1 (strongly disagree) to 5 (strongly agree). The authors reported a Cronbach's alpha coefficient score of 0.91 for the scale. However, the outcome of the pilot factor analysis of this study reduced the scale item to 21, and yielded Cronbach's alpha coefficient scores of 0.88 (self-efficacy), 0.91 (hope), 0.85 (resilience), 0.67 (optimism) and 0.94 for the whole scale of psychological capital, while the main study's factor analysis yielded a Cronbach's alpha coefficient score of 0.85 for the whole scale of PsyCap (See Appendices 1-3 for details).

\section{Occupational stress}

A nine-item scale of job stress that was developed and validated by Jamal and Baba (1992) was utilised to measure occupational stress. The measure was designed with a fivepoint Likert-type response format ranging from 1 (strongly disagree) to 5 (strongly agree). The authors reported a Cronbach's alpha coefficient score of 0.83 for the scale. However, the outcome of the pilot factor analysis of this study reduced the scale item to seven and yielded Cronbach's alpha coefficient score of 0.81 , while the main study's factor analysis yielded a Cronbach's alpha coefficient score of 0.80 for the measure of occupational stress (See appendices 1-3 for details).

\section{Organisational citizenship behaviour}

A 15-item modified version of Podsakoff, Mackenzie, Moorman and Fetter's (1990) organisational citizenship behaviour questionnaire by Argentero, Cortese and Ferretti (2008) was utilised to measure organisational citizenship behaviour. The construct consisted of altruism, conscientiousness and civic virtue sub-scales, with a fivepoint Likert-type response format ranging from 1 (Strongly disagree) to 5 (Strongly agree). Argentero et al. (2008) reported the following Cronbach's alpha coefficients for the scale: altruism $=0.81$, conscientiousness $=0.73$, civic virtue $=0.73$ and 0.84 for the whole scale of organisational citizenship behaviour. However, the outcome of the pilot factor analysis of this study reduced the scale item to 13 , and yielded Cronbach's alpha coefficients of 0.88 (altruism), 0.81 (conscientiousness), 0.86 (civic virtue) and 0.93 for the whole scale of organisational citizenship behaviour, while the main study's factor analysis yielded a Cronbach's alpha coefficient score of 0.82 for the whole scale of organisational citizenship behaviour (See appendices 1-3 for details).

\section{Statistical analysis of data}

The data generated from 1532 screened questionnaires were analysed based on the hypotheses stated, using version 20 of the Statistical Package for the Social Sciences (SPSS). Hypothesis 1 was analysed, using Pearson correlation analysis. Hypothesis 2 was analysed using multiple regression analysis, while the percentage, mean, standard deviation (SD) and the frequency of the biographical and occupational data were determined by the descriptive statistics.

\section{Ethical consideration}

Voluntary participation in the study was sought through a letter of consent, signed by each of the participants. The participants were informed about the importance of the study as the findings of the study may positively influence the government policy helping in improving their conditions of employment and service. Moreover, assurance was given to the participants with respect to confidentiality of all information supplied. Furthermore, the participants were instructed not to indicate any means of identification such as name, identity number and organisational affiliation. With utmost sense of sincerity, information concerning the study and its outcomes was accurately submitted to the appropriate institutions. Thus, it was ensured that no instances of misleading actions were demonstrated in the course of the study. The researchers also ensured that the study was conducted in a conducive environment such that it would not expose the participants to any physical or psychological hazard. The Research Ethics Committee of University of Fort Hare granted approval for ethical clearance of the study (certificate reference number: MJO071SADE01).

\section{Research results}

The results in Table 1 show the levels at which the participants possessed each of the variables of consideration in the study. For instance, the results of descriptive statistics show that the participants demonstrated a higher level of PsyCap, $\bar{X}=60.482, S D=8.493$. The results imply that the participants in the study are positively oriented about themselves.

Similarly, the results in Table 1 show that participants expressed a high level of organisational citizenship behaviour $\bar{X}=52.389, S D=6.949$ ), which also indicates that the participants are highly interested in helping their colleagues at work, at the same time ensuring that their personal and organisational goals are achieved. Likewise, the results in Table 1 further show that the participants expressed a significant amount of occupational stress $(\bar{X}=24.354$, $S D=5.402)$. The results mean that the participants have experienced some amount of occupational stress.

TABLE 1: Descriptive analysis showing the mean and standard deviation among organisational citizenship behaviour, the three dimensions of organisational citizenship behaviour, psychological capital, the four dimensions of psychological capital and occupational stress.

\begin{tabular}{lccc}
\hline Variable & $\boldsymbol{N}$ & $\overline{\boldsymbol{X}}$ & SD \\
\hline Psychological capital & 1532 & 60.4817 & 8.49292 \\
Occupational stress & 1532 & 24.3544 & 5.40185 \\
Organisational citizenship behaviour & 1532 & 52.3890 & 6.94911 \\
Self-efficacy (PsyCap) & 1532 & 20.3845 & 3.54578 \\
Hope (PsyCap) & 1532 & 20.5281 & 3.40532 \\
Resilience (PsyCap) & 1532 & 15.3544 & 2.59459 \\
Optimism (PsyCap) & 1532 & 8.0424 & 1.65358 \\
Altruism (OCB) & 1532 & 20.0020 & 3.25440 \\
Conscientiousness (OCB) & 1532 & 11.8035 & 1.97103 \\
Civic virtue (OCB) & 1532 & 20.5836 & 3.17756 \\
Valid N (list wise) & 1532 & - & - \\
\hline
\end{tabular}

$\mathrm{OCB}$, organisational citizenship behaviour; $N$, number; SD, standard deviation; $\bar{X}$, sample mean; PsyCap, psychological capital. 
The results further reveal that the participants expressed significantly higher levels of civic virtue $(\bar{X}=20.584$, $S D=3.178)$, hope $(\bar{X}=20.528, S D=3.405)$, self-efficacy $(\bar{X}=20.385, S D=3.546)$, altruism $(\bar{X}=20.002, S D=3.254)$, resilience $(\bar{X}=15.354, S D=2.595)$, conscientiousness $(\bar{X}=11.804, S D=1.971)$ and optimism $(\bar{X}=8.042, S D=1.653)$.

Hypothesis 1 was analysed by using Pearson's correlation analysis. The results of the analysis are presented in Table 2.

The data in Table 2 show that there is a positive relationship between OS and OCB $(r=0.070, p=0.01)$. Even though there is a positive relationship observed between OS and OCB, the level of the observed positive relationship between the two aforementioned variables is feeble, considering the given significance value, $0.006=0.01$ (approximated to two decimal points), which is exactly the maximum limit of acceptable value of significance at the 0.01 level (2-tailed). Therefore, based on the results and interpretations above, Hypothesis 1 , $\mathrm{H}_{0}$, is rejected, while Hypothesis $1, \mathrm{H}_{1}$, is accepted. Figure 2 depicts the relationship between OS and OCB.

The results in Table 3 show that PsyCap is a significant moderator of the relationship between OS and organisational citizenship behaviour, $F(2.1529)=8.514 ; R^{2}=0.011 ; p<0.01$. The results also indicate that occupational stress independently influences organisational citizenship behaviour $(\beta=0.070$; $t=2.738 ; p<0.05)$. However, when compared the beta value obtained from the direct influence of occupation stress $(\beta=0.070)$ with that of the moderating influence of PsyCap $(\beta=0.064)$ in the relationship between OS and organisational citizenship behaviour, the result indicates that PsyCap demonstrated a significant moderating influence in the observed relationship between OS and OCB by significantly reducing the undesirable direct influence of occupation stress on organisational citizenship behaviour.

TABLE 2: Summary of Pearson's correlation analysis showing the relationship between occupational stress and organisational citizenship behaviour.

\begin{tabular}{lcc}
\hline Variable & OCB & OS \\
\hline OCB & 1 & $0.070 \dagger$ \\
Sig. (2-tailed) & - & 0.006 \\
$N$ & 1532 & 1532 \\
OS & $0.070 \dagger$ & 1 \\
Sig. (2-tailed) & 0.006 & - \\
$N$ & 1532 & 1532 \\
\hline
\end{tabular}

$\mathrm{OCB}$, organisational citizenship behaviour; OS, occupational stress; Sig, significance; $N$, number.

$\dagger$, Correlation is significant at the 0.01 level (2-tailed).

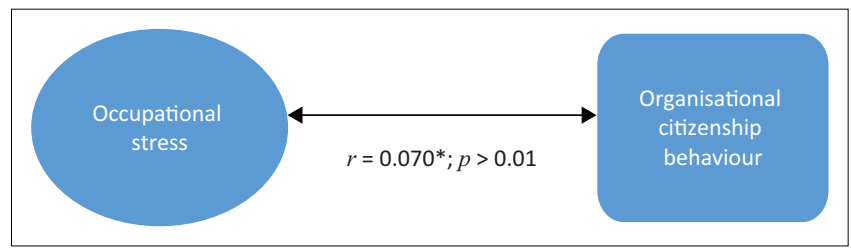

Note: Hypothesis 2 was analysed by using multiple regression analysis. The results of the analysis are presented in Table 3 .

*, Correlation is significant at the 0.01 level (2-tailed).

FIGURE 2: Relationship between occupational stress and organisational citizenship behaviour.
The results in Table 3 further show that the moderating role of PsyCap accounts for only $1 \%$ of the total variance in the relationship between OS and OCB. It thus implies that many other factors that were not considered in the study could be responsible for the remaining 99\% variance in the relationship between OS and OCB. Although the $R$ value, on the other hand, is higher (0.105), which if considered, it implies that PsyCap accounts for as much as $10 \%$ of the total variance in the relationship between OS and OCB, but it is not as reliable as the $R^{2}$ value even though it looks greater, because the statistical principle of regression theory emphasizes the fact that only the $R^{2}$ guarantees error-free values. In view of the above results and its interpretations, Hypothesis $2, \mathrm{H}_{0^{\prime}}$ is rejected, while the $\mathrm{H}_{1}$ is accepted. Figure 3 depicts the picture of PsyCap moderating the relationship between OS and organisational citizenship behaviour.

\section{Discussion}

The results presented established the hypothesised relationship and moderation in the conceptual model (Figure 1). A weak positive relationship was found existing between OS and OCB. This explains that though there is an indication of a positive relationship between OS and OCB, but the observed level of positive relationship between the two variables is not reliable enough. Thus, perhaps, it requires the introduction of one or more other positive variables to serve as moderators or mediators in order to yield a more significant and reliable relationship. These findings corroborate the reports of Uzonwanne (2014), which states that there is a weak positive relationship between OS and OCB. Similarly, Soo and Ali (2016) report further that self-initiated imposed work overload is significantly, positively related to organisational citizenship behaviour, but organisationally imposed overload is not a significant predictor of organisational citizenship behaviour.

In terms of moderation, PsyCap was found to have a significant level of moderating role in the observed positive relationship between OS and OCB. Although the results

TABLE 3: Summary of multiple regression analysis showing the moderating role of psychological capital in the relationship between occupational stress and organisational citizenship behaviour.

\begin{tabular}{lcccccc}
\hline Variable & $\boldsymbol{R}$ & $\boldsymbol{R}^{2}$ & $\boldsymbol{\beta}$ & $\boldsymbol{T}$ & $\boldsymbol{F}$ & $\boldsymbol{P}$ \\
\hline Occupational stress (OS) & - & - & 0.070 & 2.738 & - & 0.006 \\
$\begin{array}{l}\text { Psychological capital with } \\
\text { Occupational stress }\end{array}$ & 0.105 & 0.011 & 0.064 & 2.490 & 8.514 & 0.000 \\
\hline
\end{tabular}

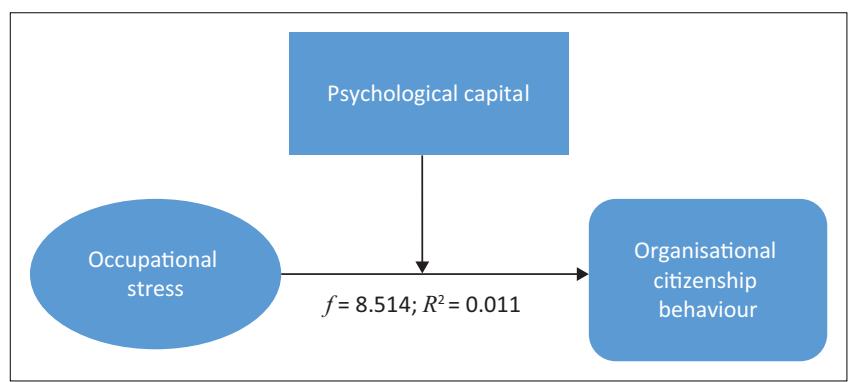

FIGURE 3: Psychological capital as a moderator of the relationship between occupational stress and organisational citizenship behaviour. 
show that there are many other variables or factors, which are of a similar nature with PsyCap, and could have also moderated the relationship between OS and organisational citizenship behaviour, but were not considered in the structured model. The observed results are supported by the findings of Aybas and Acar (2017), which show that PsyCap partially moderated and mediated the effects of opportunity enhancing HR practices and working conditions on work engagement. Similarly, Wang et al. (2017) reported that PsyCap and its components of hope and optimism are significant mediators of the relationships among work stress, work engagement and rewards.

\section{Limitations of the study and suggestions for future research}

The first noticeable shortcoming of this research relates to bias in the approach of data collection. The research only adopted the quantitative method, which limited the opinions of research respondents to the response options provided to statements in the questionnaire. This study therefore suggests that future studies should consider adopting more than one method of data collection. The second acknowledged limitation of this study is that only one moderating variable was considered in the structured model.

\section{Recommendations}

In view of the above discussion of the findings, the researchers make the following practical recommendations:

- The tertiary institutions' management, most especially of the universities, should incorporate in their academic curricula some practical simulated work exercise that will pre-expose the graduating students to the challenges at the world of work. This will build their psyche and make them mentally and emotionally ready to overcome any stressful situation that may come in their way, even in the cause of discharging of career duties or responsibilities through the positivism approach. This can be achieved by a deliberate inclusion of moderately difficult practical group assignments in the syllabus that will task each student in a group to proactively think 'outside the box' and proffer visible solutions in the form of suggestions to the problems at hand. By so doing, the students will develop reasonable levels of hope, resilience, optimism, self-efficacy and empathy along with the acquired theoretical knowledge of their disciplines, while the universities can also boast of producing capable graduates who will fit perfectly into the realities of the world of work and promptly deliver.

- The model of relationship between OS and organisational citizenship behaviour, propounded in this study, should be adopted and applied by teachers, lecturers, seminar facilitators, workshop trainers, supervisors and managers during their coaching or training sessions. Specifically, the focus should be on training the individual employees or graduates to discover their covert behavioural endowments such as PsyCap and make them refined through a systematic training process that converts the covert behavioural gifts into overt psychological assets in the form of demonstrable managerial competencies, which can enhance their performance on the job, and also enable them to be pro-social among colleagues in the work settings.

\section{Conclusion}

This study concludes that there is a positive relationship between OS and organisational citizenship behaviour. It also concludes that PsyCap is a significant moderator of the relationship between OS and organisational citizenship behaviour. The researchers therefore finally state that the study findings contribute specifically to the existing literature on occupational stress, organisational citizenship behaviour and also to the literature on employee performance management.

\section{Acknowledgements Competing interests}

The authors declare that they have no financial or personal relationships that may have inappropriately influenced them in writing this article.

\section{Authors' contributions}

J.K.A. is the PhD researcher who designed, developed and implemented the research blueprint under the supervision of T.Q.M.

\section{References}

Adebayo, S. O., \& Ogunsina, S. O. (2011). Influence of supervisory behaviour and job stress on job satisfaction and turnover intention of police personnel in Ekiti State. Journal of Management and Strategy, 2(3), 13-20. https://doi.org/10.5430/jms. v2n3p13

Adebiyi, D. R. (2013). Occupational stress among academic staff of Ekiti State University, Ado-Ekiti. European Scientific Journal, 9(4), 202-208.

Adetayo, J. O., Ajani J. O., \& Olabisi, O. (2014). An overview of the effects of job stress on employees' performance in Nigeria Tertiary Hospitals. Ekonomika, 60(4), 139-153.

Ahmad, A., Hussain, A., Saleem, M. Q., Qureshi, M. A. M., \& Mufti, N. A. (2015). Workplace stress: A critical insight of causes, effects and interventions. Technical Journal, University of Engineering and Technology, Taxila, Pakistan, 20(2), 45-55.

Aliyev, R., \& Tunc, E. (2015). Self-efficacy in counceling: The role of organizational psychological capital, job satisfaction and burnout. Procedia - Social and Behavioral Sciences, 190, 97-105.

American Psychological Association. (2013). Stress in America: Missing the health care connection. Washington, DC: American Psychological Association.

Amunkete, S. L. N. (2015). Psychological capital in Namibian state-owned enterprises: Measurement, antecedents and outcomes. Ph.D Thesis, North-West University, South Africa.

Argentero, P., Cortese, C. G., \& Ferretti, M. S. (2008). Organisational citizenship behaviour: Podsakoff et al.'s scale. TPM, 15(2), 61-75.

Arogundade, O. T., \& Lawal, O. (2016). The influence of perceived occupational stress on the organizational citizenship behaviour of bankers in Ikeja, Lagos State. European Scientific Journal, 12(17), 449-458.

Aybas, M., \& Acar, A. C. (2017). The effect of human resource management practices on employees' work engagement and the mediating and moderating role of positive psychological capital. International Review of Management and Marketing, 7(1), 363-372.

Baxter, P. E. (2010). Providing orientation programs to new graduate nurses: Points to consider. Journal for Nurses in Staff Development, 26, E12-E17. https://doi. org/10.1097/NND.0b013e3181d80319

Beheshtifar, M. \& Nazarian, R. (2013). Role of occupational stress in organizations. Interdisciplinary Journal of Contemporary Research in Business, 4(9), 648-657.

Bhattacherjee, A. (2012). Social science research: Principle, methods and practices. Textbook collection. Book 3. Athens. CreateSpace Independent Publishing Platform, http://scholarcommons.usf.edu/oa_textbooks/3

Brynien, K., \& Igoe, A. (2016). Occupational stress factsheet. PEF Health and Safety Department. New York: Public Employees Federations.

Chandra, N., \& Parvez, R. (2016). A review article: Impact of environmental and occupational stress on health. Paripex - Indian Journal of Research, 5(5), 456-457. 
Farzianpour, F., Foroushani, A. R., Kamjoo, H., \& Hosseini, S. S. (2011). Organisational citizenship behaviour (OCB) among the managers of teaching hospitals. American Journal of Economics and Business Administration 3(3), 534-542. https://doi. Journal of Economics and Business
org/10.3844/ajebasp.2011.534.542

Federal Ministry of Women Affairs \& Social Development. (2008). Nigeria Gender Statistics Book. Mitsubishi UFJ Research \& Consulting Co., Ltd, Japan.

Goh, J., Pfeffer, J., \& Zenios, S. A. (2015). Workplace stressors \& health outcomes: Health policy for the workplace. Behavioural Science \& Policy, 1(1), 43-52. https:// doi.org/10.1353/bsp.2015.0001

Gregory, A. L., Yitzhak, F., \& Steffen, R. (2016). Evidence for the need to distinguish between self-initiated and organizationally imposed overload in studies of work stress. Work \& Stress, 30(4), 337-355. https://doi.org/10.1080/02678373.2016.1 253045

Ikonne, C. N., \& Madukoma, E. (2016). An investigation of the relationship between job satisfaction, job stress and organizational citizenship behaviour: A research on librarians in Nigerian University Libraries. International Journal of Science and Research, 5(8), 480-484.

Jamal, M., \& Baba, V. V. (1992). Shiftwork and department type related to job stress, work attitudes and behavioural intentions: A study of nurses. Journal of Organisational Behaviour, 13, 449-464. https://doi.org/10.1002/job.4030130503

Karolidis, D. (2016). Organisational citizenship behaviour in the Greek public sector. Interdependent Programme of Postgraduate Studies in Business Administration, University of Macedonia. Retrieved from https://dspace.lib.uom.gr/bitstream/ 2159/18829/6/KarolidisDimitriosMsc2016.pdf

Kumari, P. \& Thapliyal, S. (2017). Studying the Impact of organizational citizenship behaviour on organizational effectiveness. International Academic Journal of Organizational Behavior and Human Resource Management, 4(1), 9-21.

Laschinger, H. K. S. (2011). Job and career satisfaction and turnover intentions of newly graduated nurses. Journal of Nursing Management, 20(4), 472-484. Advance online publication.

Lelei, J. C., Chepkwony, P. K., \& Ambrose, K. (2016). Effect of organisational citizenship behaviour on employee performance in banking sector, Nairobi County, Kenya. International Journal of Business, Humanities and Technology, 5(4), 55-61.

Li, X., Kan, D., Liu, L., Shi, M., Wang, Y., Yang, X., ...Wu, H. (2015). The mediating role of psychological capital on the association between occupational stress and job burnout among bank employees in China. International Journal of Environmental Research and Public Health, 12, 2984-3001. https://doi.org/10.3390/ijerph120302984

Luthans, F., Avolio, B. J., Avey, J. B., \& Norman, S. M. (2007). Psychological capital Measurement and relationship with performance and satisfaction. Personnel Psychology, 60, 541-572. https://doi.org/10.1111/j.1744-6570.2007.00083.x

Nawazi, N., \& Gomes, A. M. (2018). The Relationship between organizational citizenship behavior and team performance: The mediating effect of team conflict. Managemen and Organizational Studies, 5(1), 15-22. https://doi.org/10.5430/mos.v5n1p15
Niks, I., de Jonge, J., Gevers, J., \& Houtman, I. (2018). Work stress interventions in hospitals care: Effectiveness of the discovery method. International Journal of Environmental Research and Public Health, 15, 332. https://doi.org/10.3390/ of Environ

North Carolina Center for Public Health Preparedness. (2013). Two-stage cluster sampling: General guidance for use in public health assessments. University of North Carolina, Chapel Hill.

Nourani, S. S., Kohansal, D. Z., Esmaily, H., \& Hooshmand, E. (2016). The relationship between organisational citizenship behaviour, job satisfaction and occupational stress among midwives working in Healthcare Centers of Mashhad, Iran. Journal of Midwifery and Reproductive Health, 4(2), 622-630.

Paillé, P. (2011). Stressful work, citizenship behaviour and intention to leave the organization in a high turnover environment: Examining the mediating role of job satisfaction. Journal of Management Research, 3(1), 1-14.

Podsakoff, P. M., Mackenzie, S. B, Moorman, R. H., \& Fetter, R. (1990). Transformational leader behaviours and their effects on followers' trust in leader, satisfaction and organisational citizenship behaviour. The Leadership Quarterly, 1(2), 107-142. https://doi.org/10.1016/1048-9843(90)90009-7

Pradhan, R. K., Jena, L. K., \& Bhattacharya, P. (2016). Impact of psychological capital on organisational citizenship behaviour: Moderating role of emotional intelligence. Cogent Business \& Management, 3, 1-16. https://doi.org/10.1080/23311975.201 6.1194174

Shafaghat, T., Zarchi, M. K. R., \& Kavosi, Z. (2018). Occupational stress and how to confront it: A case study of a hospital in Shiraz. Hospital Practices and Research, 3(2), 64-68. https://doi.org/10.15171/hpr.2018.13

Shaheen, S., Bukhari, I., \& Adil, A. (2016). Moderating role of psychological capital between perceived organizational support and organizational citizenship behaviour and its dimensions. International Journal of Research Studies in Psychology, 5(2), 41-50. https://doi.org/10.5861/ijrsp.2016.1375

Soo, H. S., \& Ali, H. (2016). The linkage between stress and organizational citizenship behaviour. International Business Management, 10(14), 2713-2718.

The Research Advisors. (2006). Sample size table. Retrieved from http://researchadvisors.com

Uzonwanne, F. C. (2014). Depression, anxiety and stress as correlates of organizational citizenship behaviour among oil workers in Nigeria. European Journal of Globalization and Development Research, 10(1), 619-637.

Wang, X., Liu, L., Zou, F., Hao, J., \& Wu, H. (2017). Associations of occupational stressors, perceived organizational support, and psychological capital with work engagement among Chinese Female Nurses. BioMed Research International, 2017(5284628), 1-11. https://doi.org/10.1155/2017/5284628

World Health Organization. (2010). Healthy workplaces: A model for action for employers, workers, policymakers and practitioners. Geneva: WHO. 


\section{Appendix 1: Pilot study's questionnaire Section: A (Biographical and occupational information)}

1. Please mark $[\mathrm{V}] /$ indicate in the appropriate box

2. Sex: Male [ ] Female []

3. Age:

4. Marital status: Single [ ] Married [ ] Divorced [ ] Widow/Widower [ ]

5. Educational Qualification: BSc [ ] HND [ ]

6. Years of work experience:

7. Type of appointment type: Full-time [ ] Temporary/Contract [ ]

8. Rank of employment: Senior [ ] Junior [ ]

9. Type of sector: Public [ ] Private [ ]

10. Occupation:

11. Industry:

\section{Section: B}

Instructions: Below are a number of statements that may or may not apply to you. Please mark [V] in the box to indicate the extent to which you agree or disagree with each statement.

\begin{tabular}{|c|c|c|c|c|c|c|}
\hline No. & Statements & $\begin{array}{l}\text { Strongly } \\
\text { disagree }\end{array}$ & Disagree & Rarely agree & Agree & $\begin{array}{l}\text { Strongly } \\
\text { agree }\end{array}$ \\
\hline 1. & I feel confident analysing a long-term problem to find a solution. & & & & & \\
\hline 2. & I feel confident in representing my work area in meetings with management. & & & & & \\
\hline 4. & I feel confident helping to set targets or goals in my work area. & & & & & \\
\hline 5. & I feel confident contacting people outside the organisation (e.g. suppliers, customers) to discuss problems. & & & & & \\
\hline 6. & I feel confident presenting information to a group of colleagues. & & & & & \\
\hline 8. & At the present time, I am energetically pursuing my work goals. & & & & & \\
\hline 9. & There are lots of ways around any problem. & & & & & \\
\hline 10. & Right now, I see myself as being pretty successful at work. & & & & & \\
\hline 11. & I can think about many ways to reach my current work goals. & & & & & \\
\hline 12. & At this time, I am meeting the work goals that I have set for myself. & & & & & \\
\hline 13. & When I have a setback at work, I have trouble recovering from it, moving on. & & & & & \\
\hline 14. & I usually manage difficulties one way or another at work. & & & & & \\
\hline 16. & I usually take stressful things at work in stride. & & & & & \\
\hline 17. & I can get through difficult times at work because I have experienced difficulty before. & & & & & \\
\hline 18. & I feel I can handle many things at a time at this job. & & & & & \\
\hline 19. & When things are uncertain for me at work, I usually expect the best. & & & & & \\
\hline 20. & If something can go wrong for me work-wise, it will. & & & & & \\
\hline 21. & I always look on the bright side of things regarding my job. & & & & & \\
\hline 22. & I am optimistic about what will happen to me in the future as it pertains to work. & & & & & \\
\hline 23. & In this job, things never work out the way I want them to. & & & & & \\
\hline 24. & I approach this job as if 'every cloud has a silver lining'. & & & & & \\
\hline
\end{tabular}

\section{Section: C}

\begin{tabular}{|c|c|c|c|c|c|c|}
\hline No. & Statements & $\begin{array}{l}\text { Strongly } \\
\text { disagree }\end{array}$ & Disagree & Rarely agree & Agree & $\begin{array}{c}\text { Strongly } \\
\text { agree }\end{array}$ \\
\hline 25. & I have major work and fear that very little time to do it. & & & & & \\
\hline 26. & I feel so burdened that even a day without work seems bad. & & & & & \\
\hline 28. & Many people at my office are tired of the company demand. & & & & & \\
\hline 29. & My job makes me nervous. & & & & & \\
\hline 30. & The effect of my job on me is too high. & & & & & \\
\hline 32. & Sometimes, when I think about my job, I get a tight feeling in my chest. & & & & & \\
\hline 33. & I feel bad when I take a leave. & & & & & \\
\hline
\end{tabular}




\section{Section: D}

No. Statements

disagree

Strongly

34. I willingly help others who have work-related problems.

35. I am always ready to give a helping hand to those around me.

36. I help others who have heavy work load.

37. I help others who have been absent.

38. I guide new people even though it is not required.

39. I take steps to try to avoid problems with other workers.

40. I attend functions that are not required, but help the company image.

41. I attend meetings that are not mandatory, but important.

42. I read and keep up with organisation announcements, memos and so on.

43. I keep abreast of changes in the organisation.

44. I respect company rules and policies even when no one is watching me.

45. I do not take extra breaks.

46. I believe in giving an honest day's work for an honest day's pay.

47. I do my job without constant requests from my boss.

48. I am one of the most conscientious employees. 


\section{Appendix 2: Main study's questionnaire Section: A (Biographical and occupational information)}

Please mark $[\mathrm{V}] /$ indicate in the appropriate box

1. Sex: Male [ ] Female [ ]

2. Age:

3. Marital status: Single [ ] Married [ ] Divorced [ ] Widow/Widower [ ]

4. Educational Qualification: BSc [ ] HND [ ]

5. Years of work experience:

6. Type of appointment type: Full-time [ ] Temporary/Contract [ ]

7. Rank of employment: Senior [ ] Junior [ ]

8. Type of sector: Public [ ] Private [ ]

9. Occupation:

10. Industry:

\section{Section: B}

Instructions: Below are a number of statements that may or may not apply to you. Please mark [V] in the box to indicate the extent to which you agree or disagree with each statement.

\begin{tabular}{|c|c|c|c|c|c|c|}
\hline No. & Statements & $\begin{array}{l}\text { Strongly } \\
\text { disagree }\end{array}$ & Disagree & Rarely agree & Agree & $\begin{array}{c}\text { Strongly } \\
\text { agree }\end{array}$ \\
\hline 1. & I feel confident analysing a long-term problem to find a solution. & & & & & \\
\hline 2. & I feel confident in representing my work area in meetings with management. & & & & & \\
\hline 4. & I feel confident helping to set targets or goals in my work area. & & & & & \\
\hline 5. & I feel confident presenting information to a group of colleagues. & & & & & \\
\hline 6. & If I should find myself in a jam, I could think about many ways to get out of it. & & & & & \\
\hline 8. & There are lots of ways around any problem. & & & & & \\
\hline 9. & I can think about many ways to reach my current work goals. & & & & & \\
\hline 10. & At this time, I am meeting the work goals that I have set for myself. & & & & & \\
\hline 11. & I usually manage difficulties one way or another at work. & & & & & \\
\hline 12. & I usually take stressful things at work in stride. & & & & & \\
\hline 13. & I can get through difficult times at work because I' have experienced difficulty before. & & & & & \\
\hline 14. & I feel I can handle many things at a time at this job. & & & & & \\
\hline 16. & I approach this job as if 'every cloud has a silver lining'. & & & & & \\
\hline
\end{tabular}

\section{Section: C}

\begin{tabular}{|c|c|c|c|c|c|c|}
\hline No. & Statements & $\begin{array}{l}\text { Strongly } \\
\text { disagree }\end{array}$ & Disagree & Rarely agree & Agree & $\begin{array}{c}\text { Strongly } \\
\text { agree }\end{array}$ \\
\hline 17. & I have major work and fear that very little time to do it. & & & & & \\
\hline 18. & I feel that I never take a leave. & & & & & \\
\hline 20. & My job makes me nervous. & & & & & \\
\hline 21. & The effect of my job on me is too high. & & & & & \\
\hline 22. & Many a times, my job becomes a big burden. & & & & & \\
\hline
\end{tabular}




\section{Section: D}

No. Statements

Strongly

disagree

Strongly

24. I willingly help others who have work-related problems.

25. I am always ready to give a helping hand to those around me.

26. I help others who have heavy work load.

27. I help others who have been absent.

28. I guide new people even though it is not required.

29. I attend meetings that are not mandatory, but important.

30. I read and keep up with organisation announcements, memos and so on.

31. I keep abreast of changes in the organisation.

32. I respect company rules and policies even when no one is watching me.

33. I do not take extra breaks.

34. I believe in giving an honest day's work for an honest day's pay.

35. I do my job without constant requests from my boss.

36. I am one of the most conscientious employees. 


\section{Appendix 3: Participants' informed consent form}

Organisations: Department of Industrial Psychology

Research: Occupational stress and organisational citizenship behaviour

Researcher: Mr. John K. Aderibigbe, doctorate degree researcher (University of Fort Hare)

I am conducting this survey in Nigeria as my PhD research. Please, you are invited to participate in this study, because you are a graduate employee in Nigeria.

By signing this consent form, it means that you have confirmed that you:

- ...have read the participant information sheet.

- ...fully understand your role within this research.

- ...have had enough opportunity to ask any questions and have received satisfactory answers.

- ...understand that your participation in this study is completely voluntary that you are able to withdraw from the study at any time within practical limits, without penalty.

- ...understand that this research project has been reviewed by, and received ethics clearance through the supervisor in charge of this study.

- ...understand that your data will be handled in a confidential manner and no one involved in the study will know your name. The data will only be made available to Mr. John K. Aderibigbe and will be stored the library of University of Fort Hare.

- ....agree to take part in the research stated above.

- ...understand that if you have any other questions about this research you can contact John K. Aderibigbe at (201607467@ufh.ac.za). If you would like to make a complaint, please contact Prof. T.Q. Mjoli at (tmjoli@ufh.ac.za).

Signed (Participant)

Date

Signed (Researcher)

Date 